\title{
Trends in domestic energy use reduction and private renewable energy production
}

\author{
Patrick van Schijndel* \\ TU Eindhoven, Innovation Sciences, The Netherlands, VanSchijndel Consultancy, Portugal
}

\begin{abstract}
Domestic energy use can be directly influenced by personal choices. These choices include the selection of equipment (efficiency), mode of equipment use, consumer behaviour but also by self-production of electricity, space heating and/or cooling. Intelligent meters showing the actual use of electricity give insight in domestic energy use and is crucial in decreasing domestic energy use. However, households need better access to knowledge and experiences of experts to understand the potential choices to decrease their use of energy. Housing and equipment 'labelling' can give some support with these choices, but need to be more uniform and clear. Households controlling their own usage of energy and home production of electricity can make substantial savings on their energy bills. The paper describes experiences in practical situations using long term scientific and professional experiences.
\end{abstract}

Keywords: Domestic Energy, energy efficiency, renewable energy

\section{Introduction}

Domestic energy use in the (western) world consists in a large part of heating energy (winter season, applicable e.g. for USA/Canada/most parts of Europe, Asia, including Russia, China, Japan etc.), roughly 2 third. Then for 1 third, a mix of energy for hot tap water, lighting, cooking, and domestic appliances. The higher the income of the household, the more energy is used, which is a global trend. Many energy agencies expect that globally the use of domestic energy will just continue to increase due to the growing income trends in developing countries and that this can lead to energy and resource scarcities and climate affects. Developed countries, on the other hand, have shown a slight decrease in per capita energy use [1]. Besides fossil fuels used in heating (natural gas, fuel oil) also biomass and electricity are showing increasing trends for heating (heat pumps) but also in mobility (electrical cars, charged at home). This paper describes several trends with respect to:

\section{A. Possibilities to decrease of domestic energy use \\ B. Possibilities to increase production of renewable energy and use by private households}

Results in this paper comes from personal practical experiments and knowledge by the author

\footnotetext{
* Corresponding author: patrick@abcs-ict.nl
} 
combined with literature research.

\section{Innovations to decrease the use of domestic energy}

Several factors influence the amount of energy used in a household. First of all the location and built quality, also called building envelope, but also the design of the house determines the amounts of energy for space heating in colder climate zones and also cooling demand during warmer periods. In colder climate zones the domestic energy spend on heating is averagely two third [2] and this depends on the average temperatures in winter time. Modern houses are built with specific building rules to have a minimum standard of insulation. Over the last decades the insulation requirements have become more stricter. However, many existing houses, being 10 years or older, can (still) have substantial insulation improvements. This can be costly and the best options are specific per house and location, making it also complex. Besides improved insulation a clever use of sunlight, through windows, in winter time can give energy reduction for heating, when designing and building new homes or when renovating existing houses.

\subsection{Building envelope and energy labelling}

Within the EU most countries have adopted schemes that provide information of the annual heating needs of homes to potential buyers. For example in Sweden a house seller is required to inform the broker with energy bills (heating and electricity) for several years, which is then mentioned on the housing information websites [3]. In other EU countries, including e.g. the Netherlands, UK, Portugal and Germany, a system of Energy Performance Certificates (EPCs) is used where a scale from A to G is used, to list a house as very efficient (A) and therefore low in energy costs, to very inefficient $(G)$ and therefore very high in energy costs. In e.g. Germany the absolute amounts of heat and electricity per house are specified to buyers of property. 'Energy Labels' are given to houses as part of an obligatory EU rule, in which a calculated specific annual energy in $\mathrm{MJ} / \mathrm{m}^{2}$ is used to determine the energy label.

The differences between energy labeling of houses within the EU makes comparisson very difficult. In general the public understands A homes are better than e.g. E homes, but in scarce markets houses change ownership regardless of the energy efficiency class. There is some evidence that houses having better built quality, insulation values and hence a better label are awarded with higher sales prices [4] In line with electrical appliances the labeling system of houses should become the same all over the EU to increase it's impact and effectiveness in decreasing the energy need for heating but also cooling in the future. A system that couples label class and energy use per square meter per year (which can be altered per climate zone) would give more transparency. Overall, better information and transparency is needed for buyers so that the market will demand better and efficient houses $[5]$.

So called modern 'zero energy' buildings have insulation values well above minimal standards. Also windows on colder (no direct sunlight) direction are absent or minimal, while the 'sunny side' of the house has large windows or even a glass facade. By using vertical shades above the windows the sun will shine directly into the homes in a winter period (lower angle of the sun above the horizon), which gives a proper reduction in heating needs in this colder period. During summer periods, when the sun is at a higher angle, the vertical shades prevent direct sunlight and decrease the need for cooling.

Besides the 'fixed insulation value' another important contributor is the user itself who can set the temperature value. It is now common believe that heating does not need to be above 15-16 degrees Celsius. This just needs some adaption time and is more of a 
psychological value. Any degree lower will have a large effect on saving on heat costs. Of course, a lower indoor temperature must not lead to lower comfort levels or negative health effects.

For well being and comfort, the temperature of the walls is more important than the indoor temperature. Application of different housing materials, e.g. wood (warm material) in stead of concrete or stones (cold materials) can be an important factor here. Another factor is the way our houses are built: location of windows and use of sunlight in winter time. Humidity inside the house is also a factor which determines the well being. In southern Europe, although enjoying a higher outdoor temperature during the winter season, humidity and poor insulation can lead to much higher heat demands as expected from the climate regional climate conditions.

\subsection{Equipment in the house}

A topic that has been well addressed by the electronics industry, is 'Standby Power', which is the electrical energy consumption of equipment when not in use or in 'idle' mode. Standby power for most equipment has decreased over time, but it is still much better to use switchable sockets to completely switch equipment of, when not in use. This method also helps to remember to switch of devices when not in use. In the Netherlands in the 1990-2010 period, TV units (CRT) on standby power have been the cause of domestic fire incidents.

When buying house appliances nowadays, e.g. Fridge and freezers, washing machines, dishwashers, laundry dryers, the European Energy label can help choosing the right equipment. Equipment with Label $\mathrm{A}+++$ has a higher efficiency over Label $\mathrm{A}++, \mathrm{A}+, \mathrm{A}, \mathrm{B}$, $\mathrm{C}, \mathrm{D}$ and so on. The system, however, does not tell the buyers how you can use the equipment more effectively. Also, most fridges are either A or A+ and there is not enough variation on labels. One extra issue is that equipment with the highest label and efficiency are sometimes overpriced compared to equipment with label A and worse. This means that there is no general trend that a more efficient device will earn back its higher initial cost and that the price difference is not based on actual higher production costs, Also it is not so easy for everyone to calculate the best choice of equipment based on energy costs alone. Studies show that there is some effect of users to buy more efficient equipment, indicating that the labelling system has some positive effects on marketing the more efficient equipment [6].

\subsection{Equipment energy saving examples}

Following examples will show that the average home is not fully optimized in terms of energy use and energy efficiency and that common sense and sometimes some measuring can help making energy saving decisions.

\section{Example 1. Modern 2012 built Dishwasher, label A, can it be further improved?}

Using a simple electric consumption meter a new Label A dishwasher (brand Bosch) was investigated [7] on the power consumption and also to investigate the possibility for 'hot fill'. Hot fill stands for filling equipment like dishwashers and laundry washers directly with hot water, rather then letting the machine heat up the water with a electrical heating element. It was found that in ' 35 degrees Celsius mode', this A labeled equipment would constantly heat during washing mode and in final rinsing mode. There was no temperature setting, heating was a continuous process.

The temperature of the water inside the machine would reach 55 degrees Celsius and it was found out the machine will constantly heat the water and not use any thermostat or temperature sensor to unnecessary heating. This label A device could in potential save another $50 \%$ when it would have such a low cost sensor (1 euro) and stop heating at 35 
degrees $\mathrm{C}$. There exists dishwashers (label $\mathrm{A}+$ and better) of the same brand that have such sensor, however at a an $100 \%$ higher purchase price.

A label system is useful also in countries that have not yet adapted this system, but there is room for improvement, e.g. Making sure the label system is renewed from time to time so that the best equipment in the market is labeled A. Not doing so will add equipment marked $\mathrm{A}+$ or $\mathrm{A}++$, which is a bit confusing for consumers.

\section{Example 2. Replace large equipment by smaller equipment}

Common used fridges on average use around $1 \mathrm{kWh}$ a day and freezers around 1 to $3 \mathrm{kWh}$ a day. When combining these two units with a smaller fridge-freezer combination, one can safe about $2 \mathrm{kWh}$ per day, a reduction in electricity use of roughly $20 \%$. Rather than looking at the label of the equipment, total energy use becomes important too [6].

\section{Example 3. Space heating pumps can be shut-off}

Modern space heating systems will only turn on the space heating water circulation pump when there is a demand for heating the house. However, most older buildings utilize pumps that run continuously throughout the year. As older properties (build before 1990) uses pumps at around $100 \mathrm{~W}$, switching these of during summer periods can save up to $500 \mathrm{kWh}$, a saving of $15 \%$ on the yearly electricity bill.

When the heating system is in the basement and the heating system piping is $15 \mathrm{~mm}$ in diameter or larger it is even possible to switch on the pump only a short time per day and let natural convection do the work for free, this can safe up to $20 \%$ on the yearly electricity bill. Unfortunately many modern houses in the Netherlands and Germany nowadays donot have a basement anymore. Many of these houses have the heating system situated in the worst place at the highest point in the house, e.g. the attic, which requires a heating system pump and a causes a warm attic.

\section{Example 4. Hot fill your washing machine}

Most machines use electricity to heat up cold tap water to 35 degrees Celsius or higher. It is normally cheaper to use hot tap water (gas heated, wood heated, communal hot water, solar water heater etc.) when filling up the washing machine. Some machines have possibilities of a hot tap water connection, but a user can also fill up the washing machine with hot tap water before loading. Most household are unaware of this option, and equipment producers not always mention this option. The hot fill options only works if the user can disable or turn off the pump at the start of the washing process, avoiding warm water to be flushed out of the machine.

Example 4.; Hot fill your washing machine

Most machines use electricity to heat up cold tap water to 35 degrees $\mathrm{C}$ or higher. It is normally cheaper to use hot tap water (gas heated, wood heated, communal hot water, solar water heater etc.) when filling up the washing machine. Some machines have possibilities of a hot tap water connection, but a user can also fill up the washing machine with hot tap water before loading. Most household are unaware of this option, and equipment producers not always mention this option.

\subsection{How to let households use less energy?}

Consumeras understand that they should use less energy, and also there are always 'media campaigns' to update us on that topic. But ask a random households and ask them about their energy use reduction and they will tell you ' how can we? '. First start is awareness of actual 
consumption and secondly to know the potential to use less. One of the problems is the 'energy bill' which even for academic skilled is a difficult one and clearly not designed to be understandable.

Even households that control their energy spending do not know how to calculate their specific costs for electricity and heating due to the numerous costs (VAT tax, eco-tax, prize differentiation, tax benefits, transport costs etc.).

Modern meters for electricity and natural gas (space heating), also called 'smart meters', provide a way to display the actual, daily, monthly etc. Consumption on a display in the house. Deviations from the average can then be identified more quickly and it can also act as a stimulus to actively decrease the energy consumption. Research $[5,8]$ shows that energy savings of $3-5 \%$ are possible using these meters. It would be even more interesting to have a real smart meter that can tell the household whether and how the energy consumption can be decreased. Schools or local community centers could provide training to students, aged 1216 , or parents on how to check their energy use and take energy saving measures.

When every household would have a simple 10 Euro 'power meter', they could check all equipment themselves and get a better understanding on energy needs per specific equipment.

\section{The increase of renewable resources to provide domestic energy}

There have been always individuals who dreamed of being independent for their supply of water, energy, food etc. which is called autarky. This has been a niche in the past. Through drops in solar PV system prices and also incentives to sell home produced electricity and biogas to the grid has (e.g. UK and Germany), an increasing number of 'home power stations' and private funded large scale solar and wind power systems are built. On a sunny summer day PV solar plus wind electrical production in Germany, but also Portugal, Denmark etc. surpasses that of fossil and nuclear plants. In 2020 the number of households in the Netherlands that have a, mainly grid connected, solar PV system has surpassed the 1 million mark [9].

Households and companies within the EU can also choose to buy 'green' electricity, which comes from producers which utilize renewable energy to produce electricity as an alternative way to switch from fossil fuels to renewable energy sources.

Countries that in the recent past had no access to natural gas for space heating, e.g. Germany, Austria, have made a relatively early switch from coal to renewables, e.g. Waste wood from wood processing industries, in the 1990's. Following the high oil prices and higher electricity cost in Europe due to carbon taxes have made it also interesting in other countries, e.g. Sweden, Finland, Denmark, to switch the heating system to automated 'wood pellet' burners. Wood pellets are made mainly from wood bark and wood cuttings that are produced in the wood processing industries. These waste materials are compressed into $2-4 \mathrm{~cm}$ long cylindrical shapes, with a 6 or $8 \mathrm{~mm}$ diameter which make transportation easier.

Other innovation has been the use of heat pumps and drilled aquifer wells with 'relatively warm' water that provide heat for much lower costs and more efficient using electricity.

Since space heating being a major energy use contributor it makes sense that 'heat' is more and more provided in a centralized way by means of city power plants. In Sweden these run mainly on renewable, like waste cuttings and sawmill dust and the newer once produce not only heat but also electricity [10]. Construction costs of these transported heat systems are large, but they provide heat in sustainable way and one does not need to have own heater equipment.

In The Netherlands, the costs for 'heat' networks have always been considered to be high 
which has caused many potential projects for heating homes with industrial excess heat. On the long term these investments are worth while, also because of lacking alternatives of future heating systems in the Netherlands. The Netherlands has chosen to decrease it's natural gas production and therefore many new homes will have no 'gas connection'. Alternatives, like biomass for heating, are currently under pressure from different groups, questioning the sustainability of different sustainable sources.

Currently, the costs of home solar systems and the costs of lithium batteries are at a level which makes them feasible for long term investments in off-grid solutions. Also the introduction of electrical cars, which can act as a battery for storage of surplus solar PV energy and a supply at night time, will be an interesting addition to the complicated renewable energy equation

\section{Conclusion}

- Two third of domestic energy in northern Europe is used for space heating: This should be the a primary focus

- Insulation values of $90 \%$ of houses can be improved

- Setting of the indoor temperature largely affects energy use

- Window sizes and optimal use of sunlight (so called energy facades) asks for smarter home designs

- Equipment labeling is a good start to inform the public, education is even better

- Energy bills should be understandable for everyone, not knowing your costs does not help to calculate energy saving measures or renewable energy production investments

- Renewable energy production comes in reach of many household due to prices that are lower compared to grid electricity prices

\section{References}

1. BP Statistical Review of World Energy, https://www.bp.com/en/global/corporate/energyeconomics/statistical-review-of-world-energy.html

2. Johnston, I., ImpEE project (Cambridge, UK, 2005)

3. Hemnet, website www.hemnet.se (all registered properties list the annual energy costs in Swedish Krones, visisted 2020)

4. D. Brounen, N. Kok, On the economics of energy labels in the housing market, J. of Environmental economics and management, 62, 166-179 (2011)

5. Ramos et al., The role of information for energy efficiency in the residential sector, Energy Economics, 52, S17-S29 (2015)

6. C. Bjerregaard, N.F. Moeller, The impact of EU's energy labelling policy: An econometric analysis of increased transparency in the market for cold appliances in Denmark, Energy Policy, 128, 891899(2019)

7. P. VanSchijndel, A. Bekker, Consumption analysis of Bosch Dish washer (label A) during ecomode operation, internal research report, Mariannelund, Sweden, (2012)

8. C. McKerracher, J. Torriti, J., Energy consumption feedback in perspective: integrating Australian data to meta-analyses on in-home displays, Energy Efficiency, 6, 2 (2013)

9. https://www.energievergelijk.nl/nieuws/bijna-1-miljoen-woningen-met-zonnepanelen

10. http://vimmerbyenergi-miljo.se/tjanster/varme/kraftvarmeverk-tallholmen 